Enikö Kövari · Gabriel Gold

Panteleimon Giannakopoulos · Constantin Bouras

\title{
Cortical ubiquitin-positive inclusions in frontotemporal dementia without motor neuron disease: a quantitative immunocytochemical study
}

Received: 4 March 2004 / Revised: 9 April 2004 / Accepted: 13 April 2004 / Published online: 28 May 2004

(C) Springer-Verlag 2004

\begin{abstract}
Ubiquitin-positive tau-negative inclusions were initially described in the rare form of frontotemporal dementia (FTD) associated with motor neuron disease. However, recent studies have indicated that these inclusions are also present in typical FTD, which is usually characterized by nonspecific histological changes. To examine the contribution of these inclusions to neuronal loss and to explore their relationship with disease duration, we performed a quantitative immunocytochemical analysis of 38 typical FTD cases. Relationships between neuron and ubiquitin inclusion densities as well as between duration of illness and neuropathological parameters was studied using linear regression in both univariate and multivariate models. Ubiquitin-positive tau-negative intracytoplasmic inclusions were present in $65.8 \%$ of cases in the dentate gyrus, $57.9 \%$ in temporal cortex and $31.6 \%$ in frontal cortex. The highest densities of ubiquitin-positive inclusions were consistently observed in the dentate gyrus, followed by the temporal and frontal cortex. There was no statistically significant relationship between neuron and ubiquitin-positive inclusion densities in any of the areas studied. In contrast, ubiquitin-positive inclusion densities in the dentate gyrus were negatively related to the duration of illness. Our data suggest that the development of ubiquitin-related pathology is the rule and not the exception in typical FTD, yet is not causally related to neuronal loss. They also reveal that the development of ubiquitin-positive inclusion densities in the dentate gyrus may be associated with a more aggressive form of the disease.
\end{abstract}

E. Kövari · G. Gold · P. Giannakopoulos · C. Bouras (®) Departments of Psychiatry and Geriatrics, HUG Belle-Idée, University of Geneva School of Medicine,

1225 Geneva, Switzerland

Tel.: +41-22-3055358, Fax: +41-22-3055350,

e-mail: Constantin.Bouras@medecine.unige.ch

P. Giannakopoulos

Service of Old Age Psychiatry, University Hospitals of Lausanne, 1008 Prilly, Switzerland
Keywords Frontotemporal dementia $\cdot$ Motor neuron disease $\cdot$ Ubiquitin $\cdot$ Neuropathology

\section{Introduction}

Frontotemporal dementia (FTD) may represent more than $20 \%$ of degenerative dementias and is currently considered as the third most common cause of degenerative dementia after Alzheimer's disease (AD) and Lewy body dementia [32]. Although a global understanding of the molecular background of FTD is far from being achieved, one can schematically consider that this group includes a large but poorly defined subgroup of typical FTD cases characterized by nonspecific histopathological changes (such as neuronal loss, spongiosis and gliosis), two tauopathies [Pick's disease and FTD and parkinsonism linked to chromosome 17 (FTDP-17)], and one ubiquitinrelated disorder, FTD with motor neuron disease (MND) $[8,30,41]$. This latter form is characterized clinically by the presence of MND with dementia and neuropathologically by the formation of ubiquitin-positive and tau-negative intraneuronal inclusions in hippocampus and subcortical structures $[3,7,9,11,27,31,42,46]$. However, ubiquitin-positive intraneuronal inclusions and dendrites have also been reported in familial $[6,20,24,35]$ and in a few sporadic FTD cases in the absence of MND [2, 15, 18, 21, $22,36,40,47,48]$ as well as in FTDP-17 cases [17, 28, 35]. These observations question the specificity of ubiquitin-positive inclusions and their clinical relevance in the context of FTD. To address these issues, we performed a clinicopathological study of 38 sporadic FTD cases without motor neuron symptomatology, including a quantitative assessment of ubiquitin-related pathology and neuronal loss in the cerebral cortex and analysis of their relationship with disease duration.

\section{Materials and methods}

The diagnoses of FTD in all cases were based on the criteria of Lund and Manchester [5] and included progressive behavioral dis- 
Table 1 Demographic and routine neuropathological data in the present series (n.d. not determined, $T C$ temporal cortex, $F C$ frontal cortex, $F T$ frontotemporal)

\begin{tabular}{|c|c|c|c|c|c|c|c|c|c|}
\hline \multirow[t]{2}{*}{ Case } & \multirow{2}{*}{$\begin{array}{l}\text { Age/ } \\
\text { Gender }\end{array}$} & \multirow[t]{2}{*}{ Onset } & \multirow{2}{*}{$\begin{array}{l}\text { Duration } \\
\text { (years) }\end{array}$} & \multirow[t]{2}{*}{ Atrophy } & \multicolumn{2}{|c|}{ Gliosis } & \multirow{2}{*}{$\begin{array}{l}\text { Braak } \\
\text { stage }\end{array}$} & \multicolumn{2}{|c|}{ Ubiquitin positive } \\
\hline & & & & & TC & FC & & Neurons & Neurites \\
\hline 1 & $68 / \mathrm{F}$ & 58 & 10 & FT & +++ & + & 1 & Yes & Yes \\
\hline 2 & 71/M & 64 & 7 & FT & +++ & + & 1 & Yes & Yes \\
\hline 3 & $74 / \mathrm{M}$ & 64 & 10 & FT & +++ & ++ & 1 & Yes & Yes \\
\hline 4 & 74/M & 62 & 12 & FT & + & + & 1 & No & Yes \\
\hline 5 & $62 / \mathrm{M}$ & 54 & 8 & $\mathrm{~T}$ & + & ++ & 1 & Yes & Yes \\
\hline 6 & $62 / \mathrm{F}$ & 53 & 9 & FT & + & ++ & 1 & No & No \\
\hline 7 & $83 / \mathrm{F}$ & 75 & 13 & FT & ++ & + & 1 & No & Yes \\
\hline 8 & $83 / \mathrm{F}$ & 77 & 6 & FT & + & ++ & 2 & Yes & Yes \\
\hline 9 & $64 / \mathrm{M}$ & 53 & 4 & $\mathrm{~F}$ & + & ++ & 1 & Yes & Yes \\
\hline 10 & $80 / \mathrm{F}$ & 65 & 15 & FT & +++ & + & 1 & Yes & Yes \\
\hline 11 & $74 / F$ & 65 & 9 & $\mathrm{~F}$ & + & ++ & 2 & No & Yes \\
\hline 12 & $76 / F$ & 63 & 13 & FT & +++ & +++ & 1 & Yes & Yes \\
\hline 13 & $83 / \mathrm{F}$ & 75 & 8 & FT & +++ & +++ & 1 & No & No \\
\hline 14 & $89 / \mathrm{F}$ & 88 & 11 & $\mathrm{~T}$ & +++ & ++ & 1 & Yes & Yes \\
\hline 15 & $59 / \mathrm{M}$ & 52 & 7 & $\mathrm{~F}$ & + & +++ & 1 & Yes & Yes \\
\hline 16 & $73 / \mathrm{F}$ & n.d. & n.d. & $\mathrm{T}$ & ++ & + & 1 & No & Yes \\
\hline 17 & $62 / \mathrm{M}$ & 51 & 11 & $\mathrm{~T}$ & +++ & ++ & 1 & Yes & Yes \\
\hline 18 & $70 / \mathrm{F}$ & 64 & 6 & $\mathrm{~F}$ & +++ & - & 1 & Yes & Yes \\
\hline 19 & $81 / \mathrm{F}$ & 77 & 4 & $\mathrm{~T}$ & ++ & - & 2 & Yes & Yes \\
\hline 20 & $57 / \mathrm{M}$ & 57 & 9 & $\mathrm{~F}$ & +++ & ++ & 1 & Yes & Yes \\
\hline 21 & $83 / \mathrm{F}$ & 78 & 5 & $\mathrm{~T}$ & ++ & + & 1 & No & Yes \\
\hline 22 & $69 / \mathrm{M}$ & 63 & 5 & $\mathrm{~T}$ & +++ & ++ & 1 & Yes & Yes \\
\hline 23 & $76 / \mathrm{F}$ & 70 & 6 & $\mathrm{~T}$ & ++ & + & 2 & Yes & Yes \\
\hline 24 & $68 / \mathrm{M}$ & 65 & 3 & FT & - & - & 1 & No & Yes \\
\hline 25 & $85 / \mathrm{F}$ & 73 & 12 & FT & - & - & 1 & No & No \\
\hline 26 & $65 / \mathrm{F}$ & 60 & 5 & $\mathrm{~F}$ & ++ & +++ & 1 & No & Yes \\
\hline 27 & $56 / \mathrm{F}$ & 52 & 4 & FT & +++ & +++ & 2 & Yes & Yes \\
\hline 28 & $74 / F$ & 69 & 5 & FT & - & +++ & 2 & No & No \\
\hline 29 & $83 / \mathrm{F}$ & n.d. & n.d. & $\mathrm{T}$ & ++ & - & 2 & Yes & Yes \\
\hline 30 & $48 / \mathrm{M}$ & 38 & 10 & $\mathrm{~F}$ & - & - & 1 & No & No \\
\hline 31 & $65 / \mathrm{F}$ & 63 & 2 & $\mathrm{~F}$ & - & ++ & 1 & Yes & Yes \\
\hline 32 & $58 / \mathrm{F}$ & 51 & 7 & $\mathrm{~T}$ & ++ & ++ & 1 & Yes & No \\
\hline 33 & $70 / \mathrm{F}$ & 66 & 4 & FT & ++ & - & 1 & Yes & Yes \\
\hline 34 & $76 / \mathrm{F}$ & 60 & 16 & FT & ++ & - & 1 & Yes & Yes \\
\hline 35 & $75 / \mathrm{F}$ & 60 & 16 & FT & ++ & - & 1 & No & No \\
\hline 36 & $82 / \mathrm{M}$ & 80 & 2 & $\mathrm{~T}$ & +++ & + & 1 & Yes & Yes \\
\hline 37 & $81 / \mathrm{F}$ & 79 & 3 & $\mathrm{~T}$ & ++ & + & 1 & Yes & Yes \\
\hline 38 & $62 / \mathrm{F}$ & 56 & 6 & $\mathrm{~F}$ & ++ & ++ & 1 & Yes & Yes \\
\hline
\end{tabular}

order with insidious onset, affective symptoms, speech disorders, preserved orientation and praxis and selective frontotemporal atrophy (CT or MRI). Spouses and first-degree relatives were interviewed to complete the clinical history on the onset of symptoms. The age at onset was defined as the age at which the first symptom compatible with the diagnosis of FTD was observed. Since this study focused on sporadic FTD, all cases with positive family history (at least one first-degree relative with dementia before the age of 70 years) were excluded.

The series included 38 cases ( 26 women, $74.3 \pm 21.7$ years old and 12 men, $65.8 \pm 2.7$ years old), who died and were autopsied at the Psychiatric Hospital of the University of Geneva School of Medicine, Switzerland. Demographic data are summarized in Table 1 . There were 24 early-onset cases (age at onset $<65$ years). Mean age at onset was $66.5 \pm 1.9$ for women and $58.6 \pm 2.9$ for men. The duration of illness ranged from 2 to 16 years (mean \pm SD $7.7 \pm 0.6$ years). There were no gender-related differences in duration of illness. Twenty-four patients were admitted to the hospital with frontal lobe syndrome, including major behavioral disorders such as disinhibition, acts of violence and eating disturbances.
Among the remaining cases, 7 presented with early speech disorders leading to mutism and 8 with substantial decline of both episodic and semantic memory. Motor neuron symptomatology and extrapyramidal signs were absent in each case. All cases showed severe dementia at death (clinical dementia rating score of 3) [14].

The brains obtained at autopsy were fixed in $15 \%$ formalin for 4 weeks and stored in 5\% formalin. After macroscopic examination, both hemispheres were cut into $1-\mathrm{cm}$-thick coronal slices. For histological and immunohistochemical purposes, tissue blocks were taken from the inferior temporal cortex (Brodmann area 20), frontal cortex (Brodmann area 9), hippocampus including dentate gyrus, striatum and substantia nigra. Samples were embedded in paraffin and cut into $14-\mu m$-thick sections. Serial sections were stained with hematoxylin-eosin, cresyl violet and with antibodies against tau protein (AT8 monoclonal, 1:1,000, Innogenetics), ubiquitin (polyclonal, 1:100, Sigma), and $\alpha$-synuclein (monoclonal, 1:4,000, Zymed). The tissues were incubated at $4^{\circ} \mathrm{C}$ overnight with antibodies against tau and ubiquitin, and for 2 nights with the antibody against $\alpha$-synuclein. Following incubation, sections were pro- 
cessed by the PAP method using 3,3'-diaminobenzidine as a chromogen, as previously described [25].

Neuron and ubiquitin-positive and tau-negative intraneuronal inclusion densities were estimated using the optical dissector, an unbiased stereological counting method implying that all regions within the structure of interest have an equal chance of being analyzed (i.e., there is no bias in sampling), and that counts do not depend on variables such as the size and shape of neurons [12, 37, $43,44]$. The technique relies on a three-dimensional counting box located entirely within the tissue section, and objects are quantified by focusing in the section depth (i.e., in the $\mathrm{z}$ axis). The fact that the three-dimensional counting box is located within the section and the existence of exclusion (forbidden) planes guarantee that each neuron is counted only once [12, 37, 43, 44]. Total cell and neurofibrillary tangle (NFT) numbers were not obtained in the present study due to the fact that only the anterior portion of the hippocampus and only topographically equivalent samples of areas 9 and 20 were available for analysis. The volume of these samples was variable rendering comparison of total cell numbers impossible from case to case. For this reason, neuron and ubiquitin-positive inclusion densities per $\mathrm{mm}^{3}$ were counted on 1 in 10 sections, $500 \mu \mathrm{m}$ apart. Ten optical dissectors were placed on a random grid covering the area of interest to provide a systematic sampling paradigm for each region and layer of interest. Densities were counted using a Zeiss Axioplan microscope $(\times 100$ objective). In addition, the presence or absence of ubiquitin-positive neurites was noted. The presence and severity of concomitant AD pathology was determined using Braak stages for NFT [4].

After normalization of the neuropathological variables, the relationship between neuron densities (dependent variable) and age and ubiquitin inclusion densities (independent variables) in each area was studied using linear regression in both univariate and multivariate models. For clinicopathological correlations, the association between duration of illness (as the dependent variable) and neuropathological parameters (as the independent variables) was studied using the same statistical method.

\section{Results}

Symmetrical bilateral cerebral atrophy was present in 27 cases. A hemispheric predominance was observed in the remaining cases ( 7 in left and 4 in right hemisphere). In most cases, the cerebral atrophy was equally present in frontal and temporal cortex. However, 9 cases showed a predominant frontal lobe involvement, whereas in 12 cases the temporal cortex was preferentially affected. Microscopic examination revealed neuronal loss and vacuolation mainly in cortical layers II and III in all cases. Mod-

Table 2 Ubiquitin-inclusion and neuron densities $\left(\right.$ per $\mathrm{mm}^{3}$ ) in the present series ( $D G$ dentate gyrus, $T C$ temporal cortex, $F C$ frontal cortex)

\begin{tabular}{lrcr}
\hline & Median & $25 \%$ & \multicolumn{1}{c}{$75 \%$} \\
\hline DG & & & \\
Ubiquitin & $9,996.0$ & 0 & $27,988.8$ \\
Neurons & $331,867.2$ & $298,880.4$ & $369,185.6$ \\
TC & & & \\
Ubiquitin & 249.9 & 0 & 999.6 \\
Neurons & $16,993.0$ & $14,994.4$ & $23,990.0$ \\
FC & & & \\
Ubiquitin & 0 & 0 & 249.9 \\
Neurons & $27,155.5$ & $21,991.0$ & $31,987.0$ \\
\hline
\end{tabular}

erate to severe cortical gliosis was present in 26 cases in the temporal cortex and 19 cases in the frontal cortex. All cases showed minimal NFT formation compatible with normal aging (31 cases with Braak stage I; 7 cases with Braak stage II). There were no other forms of tau pathology such as Pick bodies or glial tau inclusions nor $\alpha$-synuclein-immunoreactive inclusions. Macrovascular pathology such as small macroinfarcts and lacunes were absent in all cases.

Neuron and ubiquitin-positive inclusions densities in the dentate gyrus, temporal and frontal cortex in the present series are summarized in Table 2. Ubiquitin-positive tau-negative intracytoplasmic inclusions were present in 25 cases $(65.8 \%)$. They were most frequent in the dentate gyrus $(65.8 \%$ of cases) compared to the temporal $(57.9 \%)$ and frontal cortex (31.6\%). Two types of ubiquitin inclusions were observed: the "crescent-type" was mainly seen in the neocortex, whereas the "spheric-type" was found in the dentate gyrus (Fig. 1a, b) [19]. All these cases also displayed ubiquitin-positive neurites. Five other cases had isolated ubiquitin-positive and tau-negative neurites; four in both frontal and temporal cortex and one in the temporal cortex. The highest densities of ubiquitin-positive inclusions were consistently observed in the dentate gyrus, followed by the temporal and frontal cortex. Ubiquitinpositive neurites were consistently present in the neostriatum in both cases with and without cortical inclusions. In contrast, very rare round or crescent inclusions were present in the neostriatum only in cases with cortical inclusions. Substantia nigra was free of inclusions in all cases. There were no cases with intranuclear ubiquitin-positive inclusions in any of the areas studied.

Regression analyses showed no significant relationship between the neuropathological variables and age. This was also the case between neuron and ubiquitin-positive inclusion densities in the areas studied. There was a positive relationship between ubiquitin-positive inclusion densities in dentate gyrus and both temporal [regression coefficient: 5.14, 95\% confidence intervals $(\mathrm{CI}): 1.47,8.81, P<0.01]$ and frontal (regression coefficient: $2.98,95 \% \mathrm{CI}: 1.19$, $4.19, P<0.05)$ cortex. In a univariate model, ubiquitin-positive inclusion densities in the dentate gyrus were significantly related to the duration of illness (regression coefficient: -1.03 , 95\% CI: $-1.06,-0.86, P<0.05$ ) (Figs. 1c-e, 2). This association persisted in a multivariate model, which included Braak NFT staging and age (regression coefficient: $-0.75,95 \% \mathrm{CI}:-1.20,-0.37, P<0.05)$. Ubiquitinpositive inclusion densities in areas 9 and 20 and neuron densities did not correlate with the duration of illness.

\section{Discussion}

The strengths of the present study include the large series of prospectively documented typical FTD cases, concomitant assessment of neuron and ubiquitin-positive inclusion densities and use of multivariate models for statistical analysis. Our data reveal that the presence of ubiquitin-positive tau-negative inclusions is the rule and not the exception in 


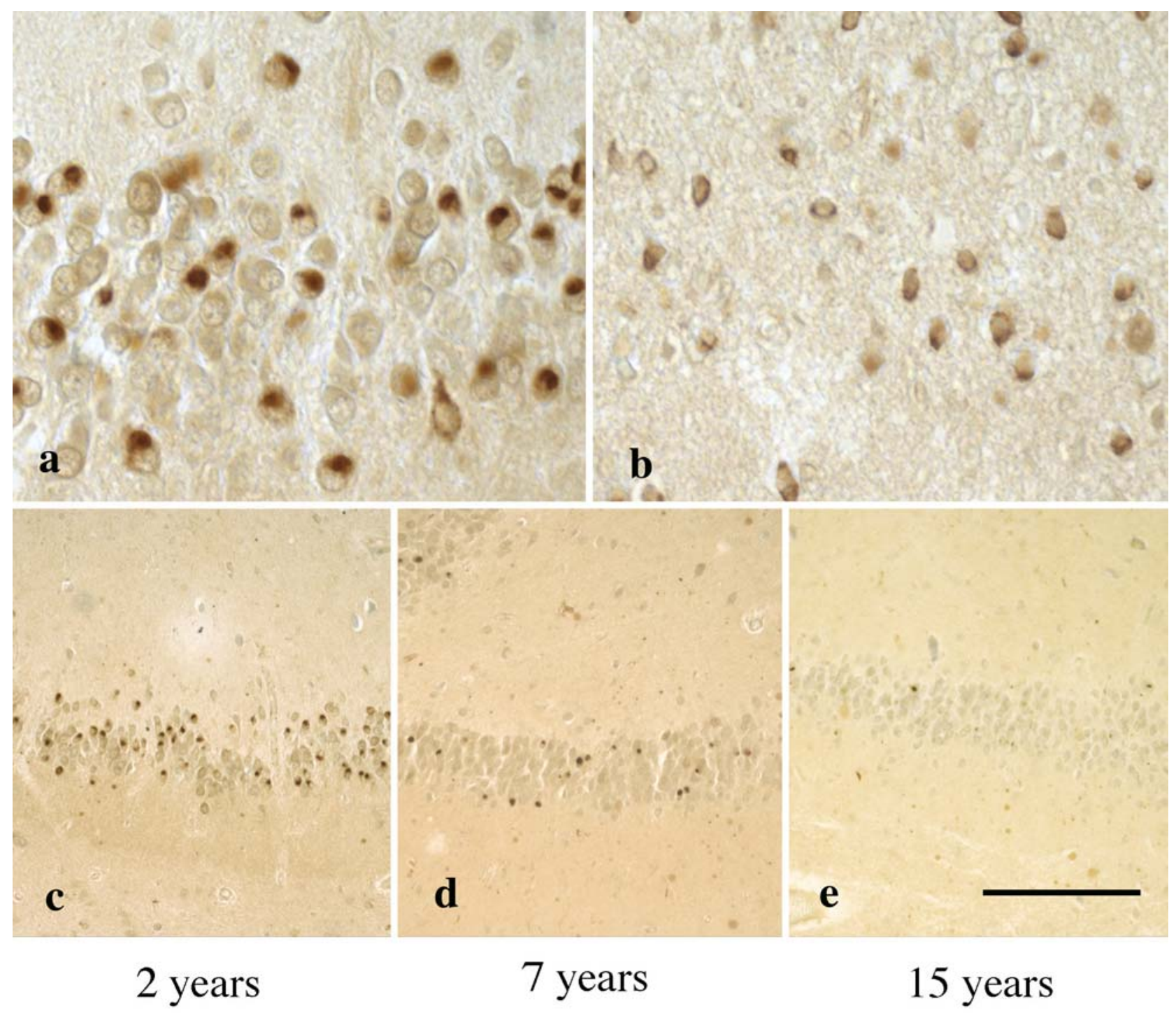

Fig. 1 "Spheric" inclusion in the dentate gyrus (a) and "crescent" inclusions in the superficial layer of the temporal cortex (b). Representative examples for ubiquitin-inclusion densities as a function of disease duration $(\mathbf{c}-\mathbf{e})$. Sections were stained with antibody against ubiquitin (see text for details). Bar a, b $50 \mu \mathrm{m}$; c-e $200 \mu \mathrm{m}$

typical FTD cases. They also show that unlike neurons the quantitative assessment of these inclusions may be a neuropathological marker of disease duration.

The presence of ubiquitin-positive tau-negative intraneuronal inclusions within the cerebral cortex and subcortical structures has been long considered as a key neuropathological feature of MND with dementia [16, 45] or FTD with MND [3, 5, 7, 9, 11, 17, 23, 27, 31, 39, 42, 46]. Despite several contributions based on small series, the presence of ubiquitin-related pathology within the cerebral cortex is still considered a rare phenomenon in typical FTD cases [2, 6, 15, 18, 21, 22, 24, 34, 35, 40, 47, 48]. However, a recent population-based study of FTD in Netherlands indicated that $25 \%$ of typical FTD cases displayed ubiquitin-positive inclusions [36]. Our data go beyond these findings in that they indicate that the appear- ance of ubiquitin-positive inclusions and neurites is an age-unrelated phenomenon, which occurs in the majority of typical FTD cases mainly in the dentate gyrus of the hippocampus and to a lesser degree in the temporal and frontal neocortex. In conjunction with the description of these inclusions in familial FTDP-17 cases (with or without tau mutations) [17, 28, 35], our findings suggest that the development of ubiquitin-related changes within the cerebral cortex is not related to a specific pathogenetic mechanism but rather represents one of the various neuropathological hallmarks of FTD spectrum. In this respect, the low percentages of neurons containing ubiquitin-positive inclusions and the absence of significant relationship between ubiquitin-positive inclusion and neuron densities in the present study strongly suggest that ubiquitin-related pathology does not play a key role in the severe neuronal loss observed in the present cases. Similar quantitative data were obtained using the same counting methodology in a recent morphometric study of nine familial FTD cases with ubiquitin-positive tau-negative inclusions [6]. These observations point to the complex relationships between the development of ubiquitin-positive inclusions and cell death 


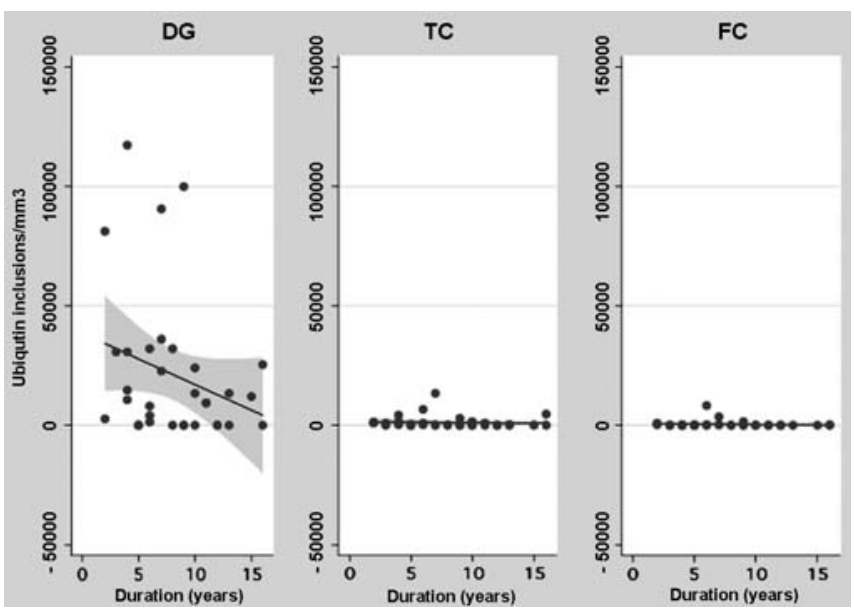

Fig. 2 Scatter plots illustrating the negative correlation between duration of illness and ubiquitin-positive inclusions densities (in $\left.\mathrm{mm}^{3}\right)$ in the DG and the absence of correlation in TC and FC ( $D G$ dentate gyrus, $T C$ temporal cortex, $F C$ frontal cortex)

in FTD. Although the role of ubiquitin-positive inclusions in this disorder is not fully understood, several recent contributions suggest that their formation is related to a dysfunction of the ubiquitin proteasome system of intracellular proteolysis, which is essential for cell viability $[1,26]$. In particular, an accumulation of a mutant form of the ubiquitin-B (UBB+1) was recently reported in FTD, further supporting an impairment of the ubiquitin-proteasome system in this disorder [10]. However, it should be kept in mind that the proteasome inhibition observed in neurons containing ubiquitin-positive inclusions may induce the activation of cell defense mechanisms, such as heat-shock responses, ultimately leading to neuroprotection [13].

Our results also show that ubiquitin-positive inclusion densities in the dentate gyrus were negatively related to the disease duration. Although weak, this relationship was robust since it persisted after controlling for age and Braak NFT staging. The accumulation of ubiquitin-positive inclusions in dentate gyrus in cases with a shorter disease duration may be a marker of a more aggressive form of FTD. Unfortunately, all cases studied presented with severe dementia (CDR score of 3 ) so that it was not possible to examine further the relationship between clinical outcome and neuropathological variables. Importantly, neuron densities did not correlate with disease duration in the present series. This finding should be interpreted in conjunction with recent studies, which identified molecular mechanisms surrounding neuronal loss in typical FTD. In particular, apoptotic phenomena in both neurons and astrocytes $[29,33,38]$ as well as a depletion of all six tau isoforms [49] have been described in this disease, both contributing to rapid neuronal death. It is thus likely that neuronal loss in typical FTD cases is neither a progressive phenomenon which would be expected to be more pronounced with increased disease duration nor a marker of disease aggressiveness.

Two main limitations should be considered when discussing our findings. First, the present series is not repre- sentative of the whole spectrum of typical FTD cases without motor neuron symptomatology since it does not includes cases with semantic dementia or primary progressive aphasia. Moreover, neuron densities per cube millimeter and not total neuron numbers were obtained from the present sample. Although we used optical dissector to limit selection biases, the absence of a rigorous stereological design may influence the validity of clinicopathological correlations. Future stereological studies in large autopsy series of well-documented FTD cases with various degrees of clinical severity are needed to elucidate the clinical impact of the different types of neuropathological changes observed in this heterogeneous clinical condition.

Acknowledgements We thank Mrs. P. Lovero and M. SuriniDemiri for the excellent technical assistance.

\section{References}

1. Alves-Rodrigues A, Gregori L, Figueiredo-Pereira ME (1998) Ubiquitin, cellular inclusions and their role in neurodegeneration. Trends Neurosci 21:516-520

2. Bergmann M, Kuchelmeister K, Schmid KW, Kretzschmar HA, Schroder R (1996) Different variants of frontotemporal dementia: a neuropathological and immunohistochemical study. Acta Neuropathol 92:170-179

3. Bigio EH, Lipton AM, White CL 3rd, Dickson DW, Hirano A (2003) Frontotemporal and motor neurone degeneration with neurofilament inclusion bodies: additional evidence for overlap between FTD and ALS. Neuropathol Appl Neurobiol 29:239253

4. Braak H, Braak E (1991) Neuropathological stageing of Alzheimer-related changes. Acta Neuropathol 82:239-259

5. Brun A, Englund B, Gustafson L, Passant U, Mann D, Neary D, Snowden JS (1994) Clinical and neuropathological criteria for frontotemporal dementia. The Lund and Manchester Groups. J Neurol Neurosurg Psychiatry 57:416-418

6. Cairns NJ, Brannstrom T, Khan MN, Rossor MN, Lantos PL (2003) Neuronal loss in familial frontotemporal dementia with ubiquitin-positive, tau-negative inclusions. Exp Neurol 181:319_ 326

7. Deymeer F, Smith TW, DeGirolami U, Drachman DA (1989) Thalamic dementia and motor neuron disease. Neurology 39:58-61

8. Dickson DW (2001) Neuropathology of Pick's disease. Neurology 56: S16-20

9. Ferrer I, Roig C, Espino A, Peiro G, Matias Guiu X (1991) Dementia of frontal lobe type and motor neuron disease. A Golgi study of the frontal cortex. J Neurol Neurosurg Psychiatry 54:932-934

10. Fischer DF, De Vos RA, Van Dijk R, De Vrij FM, Proper EA, Sonnemans MA, Verhage MC, Sluijs JA, Hobo B, Zouambia M, Steur EN, Kamphorst W, Hol EM, Van Leeuwen FW (2003) Disease-specific accumulation of mutant ubiquitin as a marker for proteasomal dysfunction in the brain. FASEB J 17:2014-2024

11. Forno LS, Langston JW, Herrick MK, Wilson JD, Murayama S (2002) Ubiquitin-positive neuronal and tau 2-positive glial inclusions in frontotemporal dementia of motor neuron type. Acta Neuropathol 103:599-606

12. Gomez-Isla T, Price JL, McKeel DW Jr, Morris JC, Growdon JH, Hyman BT (1996) Profound loss of layer II entorhinal cortex neurons occurs in very mild Alzheimer's disease. J Neurosci 16:4491-4500

13. Hope AD, Silva R de, Fischer DF, Hol EM, Leeuwen FW van, Lees AJ (2003) Alzheimer's associated variant ubiquitin causes inhibition of the 26S proteasome and chaperone expression. J Neurochem 86:394-404 
14. Hughes CP, Berg L, Danziger WL, Coben LA, Martin RL (1982) A new clinical scale for the staging of dementia. Br J Psychiatry 140:566-572

15. Ikeda K, Akiyama H, Arai T, Ueno H, Tsuchiya K, Kosaka K (2002) Morphometrical reappraisal of motor neuron system of Pick's disease and amyotrophic lateral sclerosis with dementia. Acta Neuropathol 104:21-28

16. Ikemoto A, Hirano A, Akiguchi I, Kimura J (1997) Comparative study of ubiquitin immunoreactivity of hippocampal granular cells in amyotrophic lateral sclerosis with dementia, Guamanian amyotrophic lateral sclerosis and Guamanian parkinsonism-dementia complex. Acta Neuropathol 93:265-570

17. Iseki E, Li F, Odawara T, Hino H, Suzuki K, Kosaka K, Akiyama H, Ikeda K, Kato M (1998) Ubiquitin-immunohistochemical investigation of atypical Pick's disease without Pick bodies. J Neurol Sci 159:194-201

18. Jackson M, Lennox G, Lowe J (1996) Motor neurone diseaseinclusion dementia. Neurodegeneration 5:339-350

19. Kawashima T, Doh-ura K, Kikuchi H, Iwaki T (2001) Cognitive dysfunction in patients with amyotrophic lateral sclerosis is associated with spherical or crescent-shaped ubiquitinated intraneuronal inclusions in the parahippocampal gyrus and amygdala, but not in the neostriatum. Acta Neuropathol 102: 467-472

20. Kertesz A, Kawarai T, Rogaeva E, St George-Hyslop P, Poorkaj P, Bird TD, Munoz DG (2000) Familial frontotemporal dementia with ubiquitin-positive, tau-negative inclusions. Neurology 54:818-827

21. Kinoshita A, Tomimoto H, Tachibana N, Suenaga T, Kawamata T, Kimura T, Akiguchi I, Kimura J (1996) A case of primary progressive aphasia with abnormally ubiquitinated neurites in the cerebral cortex. Acta Neuropathol 92:520-524

22. Kinoshita A, Tomimoto H, Suenaga T, Akiguchi I, Kimura J (1997) Ubiquitin-related cytoskeletal abnormality in frontotemporal dementia: immunohistochemical and immunoelectron microscope studies. Acta Neuropathol 94:67-72

23. Konagaya M, Sakai M, Matsuoka Y, Konagaya Y, Hashizume Y (1998) Upper motor neuron predominant degeneration with frontal and temporal lobe atrophy. Acta Neuropathol 96:532536

24. Kövari E, Leuba G, Savioz A, Saini K, Anastasiu R, Miklossy J, Bouras C (2000) Familial frontotemporal dementia with ubiquitin inclusion bodies and without motor neuron disease. Acta Neuropathol 100:421-426

25. Kövari E, Gold G, Herrmann FR, Canuto A, Hof PR, Bouras C, Giannakopoulos P (2003) Lewy body densities in the entorhinal and anterior cingulate cortex predict cognitive deficits in Parkinson's disease. Acta Neuropathol 106:83-88

26. Lang-Rollin I, Rideout H, Stefanis L (2003) Ubiquitinated inclusions and neuronal cell death. Histol Histopathol 18:509517

27. Mackenzie IR, Feldman H (2004) Extrapyramidal features in patients with motor neuron disease and dementia; a clinicopathological correlative study. Acta Neuropathol 107:336-340

28. Mann DM, South PW, Snowden JS, Neary D (1993) Dementia of frontal lobe type: neuropathology and immunohistochemistry. J Neurol Neurosurg Psychiatry 56:605-614

29. Martin JA, Craft DK, Su JH, Kim RC, Cotman CW (2001) Astrocytes degenerate in frontotemporal dementia: possible relation to hypoperfusion. Neurobiol Aging 22:195-207

30. McKhann GM, Albert MS, Grossman M, Miller B, Dickson D, Trojanowski JQ (2001) Clinical and pathological diagnosis of frontotemporal dementia: report of the Work Group on Frontotemporal Dementia and Pick's Disease. Arch Neurol 58: 1803-1809

31. Mochizuki A, Komatsuzaki Y, Iwamoto H, Shoji S (2004) Frontotemporal dementia with ubiquitinated neuronal inclusions presenting with primary lateral sclerosis and parkinsonism: clinicopathological report of an autopsy case. Acta Neuropathol 107:337-380
32. Neary D, Snowden JS, Gustafson L, Passant U, Stuss D, Black S, Freedman M, Kertesz A, Robert PH, Albert M, Boone K, Miller BL, Cummings J, Benson DF (1998) Frontotemporal lobar degeneration: a consensus on clinical diagnostic criteria. Neurology 51:1546-1554

33. Nichol KE, Kim R, Cotman CW (2001) Bcl-2 family protein behavior in frontotemporal dementia implies vascular involvement. Neurology 56:S35-40

34. Odawara T, Iseki E, Kanai A, Arai T, Katsuragi T, Hino H, Furukawa Y, Kato M, Yamamoto T, Kosaka K (2003) Clinicopathological study of two subtypes of Pick's disease in Japan. Dement Geriatr Cogn Disord 15:19-25

35. Rosso SM, Kamphorst W, Graaf B de, Willemsen R, Ravid R, Niermeijer MF, Spillantini MG, Heutink P, Swieten JC van (2001) Familial frontotemporal dementia with ubiquitin-positive inclusions is linked to chromosome 17q21-22. Brain 124: 1948-1957

36. Rosso SM, Donker Kaat L, Baks T, Joosse M, Koning I de, Pijnenburg Y, Jong D de, Dooijes D, Kamphorst W, Ravid R, Niermeijer MF, Verheij F, Kremer HP, Scheltens P, Duijn CM van, Heutink P, Swieten JC van (2003) Frontotemporal dementia in The Netherlands: patient characteristics and prevalence estimates from a population-based study. Brain 126:2016-2022

37. Sterio DC (1984) The unbiased estimation of number and sizes of arbitrary particles using the disector. J Microsc 134:127-136

38. Su JH, Nichol KE, Sitch T, Sheu P, Chubb C, Miller BL, Tomaselli KJ, Kim RC, Cotman CW (2000) DNA damage and activated caspase-3 expression in neurons and astrocytes: evidence for apoptosis in frontotemporal dementia. Exp Neurol 163:9-19

39. Talbot PR (1996) Frontal lobe dementia and motor neuron disease. J Neural Transm Suppl 47:125-132

40. Tolnay M, Probst A (1995) Frontal lobe degeneration: novel ubiquitin-immunoreactive neurites within frontotemporal cortex. Neuropathol Appl Neurobiol 21:492-497

41. Tolnay M, Probst A (2001) Frontotemporal lobar degeneration. An update on clinical, pathological and genetic findings. Gerontology 47:1-8

42. Toyoshima Y, Piao YS, Tan CF, Morita M, Tanaka M, Oyanagi K, Okamoto K, Takahashi H (2003) Pathological involvement of the motor neuron system and hippocampal formation in motor neuron disease-inclusion dementia. Acta Neuropathol 106:50-56

43. West MJ (1993) New stereological methods for counting neurons. Neurobiol Aging 14:275-285

44. West MJ, Coleman PD, Flood DG, Troncoso JC (1994) Differences in the pattern of hippocampal neuronal loss in normal ageing and Alzheimer's disease. Lancet 344:769-772

45. Wightman G, Anderson VE, Martin J, Swash M, Anderton BH, Neary D, Mann D, Luthert P, Leigh PN (1992) Hippocampal and neocortical ubiquitin-immunoreactive inclusions in amyotrophic lateral sclerosis with dementia. Neurosci Lett 139:269274

46. Woulfe J, Kertesz A, Munoz DG (2001) Frontotemporal dementia with ubiquitinated cytoplasmic and intranuclear inclusions. Acta Neuropathol 102:94-102

47. Yaguchi M, Okamoto K, Nakazato Y (2003) Frontotemporal dementia with cerebral intraneuronal ubiquitin-positive inclusions but lacking lower motor neuron involvement. Acta Neuropathol 105:81-85

48. Yang Y, Schmitt HP (2001) Frontotemporal dementia: evidence for impairment of ascending serotoninergic but not noradrenergic innervation. Immunocytochemical and quantitative study using a graph method. Acta Neuropathol 101:256-270

49. Zhukareva V, Vogelsberg-Ragaglia V, Van Deerlin VM, Bruce J, Shuck T, Grossman M, Clark CM, Arnold SE, Masliah E, Galasko D, Trojanowski JQ, Lee VM (2001) Loss of brain tau defines novel sporadic and familial tauopathies with frontotemporal dementia. Ann Neurol 49:165-175 